\title{
Mast cells aggravate sepsis by inhibiting peritoneal macrophage phagocytosis
}

\author{
Albert Dahdah, ${ }^{1,2}$ Gregory Gautier,, ${ }^{1,2}$ Tarik Attout,, ${ }^{1,2}$ Frédéric Fiore, ${ }^{3,4,5}$ Emeline Lebourdais,, ${ }^{1,2}$ Rasha Msallam, ${ }^{6,7}$ Marc Daëron, ${ }^{8,9}$ \\ Renato C. Monteiro, ${ }^{1,2}$ Marc Benhamou, ,,2 Nicolas Charles, ${ }^{1,2}$ Jean Davoust, ${ }^{6,7}$ Ulrich Blank, ${ }^{1,2}$ Bernard Malissen, ${ }^{3,4,5,9}$ and Pierre Launay ${ }^{1,2}$ \\ IINSERM U1149, Paris, France. 'Université Paris Diderot, Sorbonne Paris Cité, Laboratoire d'Excellence INFLAMEX, Paris, France. ${ }^{3}$ Centre d'Immunophénomique, Aix Marseille Université, Marseille, France. \\ ${ }^{4}$ INSERM US012, Marseille, France. ${ }^{5}$ CNRS UMS 3367, Marseille, France. ${ }^{6}$ INSERM U1013, Paris, France. ${ }^{7}$ Université Paris René Descartes, Sorbonne Paris Cité, Paris, France. ${ }^{8}$ Institut Pasteur, \\ Département d'Immunologie, Paris, France. 'entre d'Immunologie de Marseille Luminy, INSERM U1104-CNRS UMR 7280, Marseille, France.
}

Controlling the overwhelming inflammatory reaction associated with polymicrobial sepsis remains a prevalent clinical challenge with few treatment options. In septic peritonitis, blood neutrophils and monocytes are rapidly recruited into the peritoneal cavity to control infection, but the role of resident sentinel cells during the early phase of infection is less clear. In particular, the influence of mast cells on other tissue-resident cells remains poorly understood. Here, we developed a mouse model that allows both visualization and conditional ablation of mast cells and basophils to investigate the role of mast cells in severe septic peritonitis. Specific depletion of mast cells led to increased survival rates in mice with acute sepsis. Furthermore, we determined that mast cells impair the phagocytic action of resident macrophages, thereby allowing local and systemic bacterial proliferation. Mast cells did not influence local recruitment of neutrophils and monocytes or the release of inflammatory cytokines. Phagocytosis inhibition by mast cells involved their ability to release prestored IL-4 within 15 minutes after bacterial encounter, and treatment with an IL-4-neutralizing antibody prevented this inhibitory effect and improved survival of septic mice. Our study uncovers a local crosstalk between mast cells and macrophages during the early phase of sepsis development that aggravates the outcome of severe bacterial infection.

\section{Introduction}

Sepsis is a life-threatening condition described as a syndrome of infection complicated by acute organ dysfunction. It is still a leading cause of death in intensive care units despite early aggressive antibiotic treatments to control bacterial infection. Septic peritonitis is caused by an overwhelming inflammatory reaction of the host following the invasion of the peritoneal cavity by microorganisms (1). The role played by extravasated neutrophils and inflammatory monocytes during septic peritonitis has been extensively studied (2). However, the influence of local sentinel cells, such as as mast cells, which reside in the peritoneal cavity and are able to respond during the early phase of infection remains poorly understood.

Mast cells are particularly well represented among hematopoietic effectors in the peritoneum. These tissue-resident cells, which were originally assigned a role in allergic reactions, are increasingly recognized as being key regulatory cells that are involved in the inflammatory process (3). Mast cells appear to play both proinflammatory and antiinflammatory roles, depending on the timing, strength, or type (acute or chronic) of inflammatory disorder $(4,5)$, and an important aspect of this function is the control of other immune cells such as lymphocytes,

Authorship note: Albert Dahdah and Gregory Gautier contributed equally to this work Bernard Malissen and Pierre Launay are co-senior authors.

Conflict of interest: The authors have declared that no conflict of interest exists. Submitted: January 14, 2014; Accepted: July 24, 2014.

Reference information: / Clin Invest. 2014;124(10):4577-4589. doi:10.1172/JCI75212. neutrophils, and monocytes through the ability of mast cells to secrete various types of inflammatory mediators (6). One hallmark of mast cells is that they store many of these mediators, including cytokines, within secretory compartments, ready for immediate release upon activation (7). However, little is known about the way mast cells interact with other tissue-resident cells during an inflammatory response.

Cecal ligation and puncture (CLP), an acute model of sepsis, has been extensively used to assess the specific role innate cells play in the development of the early stages of inflammation. We and others have shown that infiltrating monocytes and macrophages can play a crucial role in the resolution of sepsis $(8,9)$. However, although addressed in several studies, the role of peritoneal mast cells (PMCs) in the pathology of sepsis remains unclear, largely due to the lack of appropriate animal models (10-17). Mast cell-deficient $K i t^{W / W-v}$ and $\mathrm{Kit}^{W-s h / W-s h}$ mice, which are often used to study the role of mast cells in inflammation, carry mutations in the Kit (CD117) locus coding for the stem cell factor receptor and have additional hematopoietic abnormalities, such as neutrophilia and a deficiency of peritoneal macrophages, that likely influence the outcome of inflammatory reactions $(17,18)$.

To study the role of mast cells in severe sepsis, therefore, we generated a mouse model with no adventitious hematopoietic abnormalities and that allowed the conditional ablation of mast cells and basophils. After repopulation of basophils and following the induction of acute CLP, we demonstrated that mast cells play a detrimental role by promptly inhibiting the phagocytic capacity of resident macrophages and hence controlling the early stages of 
A

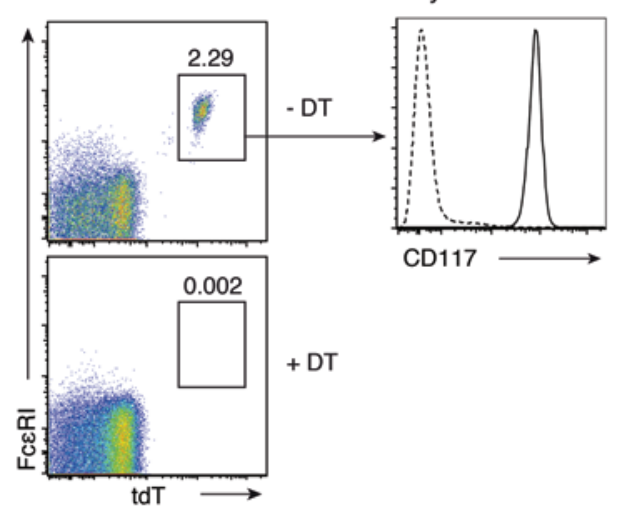

B

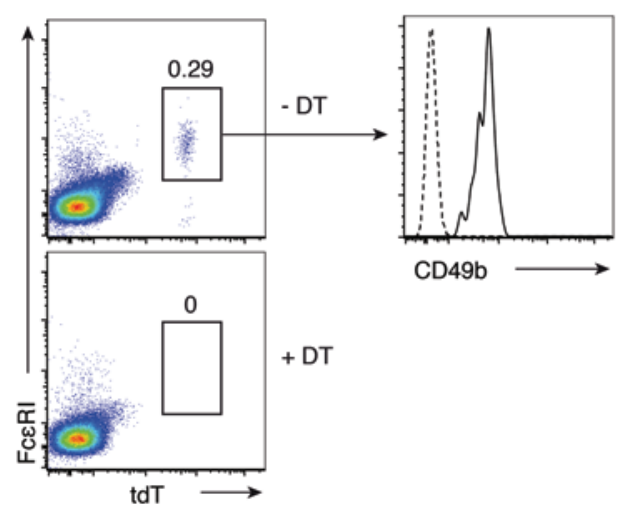

Skin

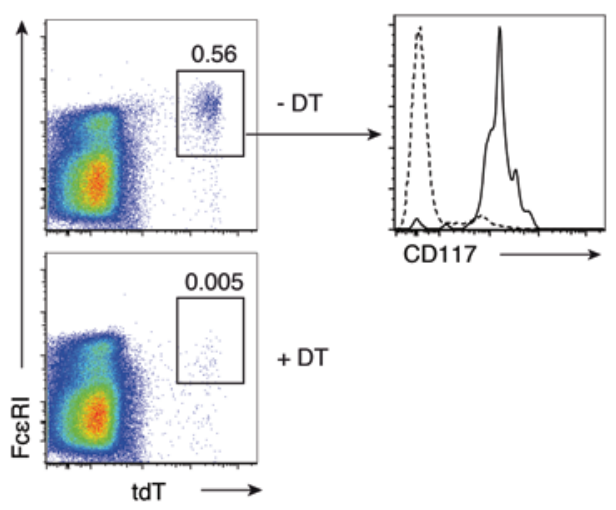

Spleen

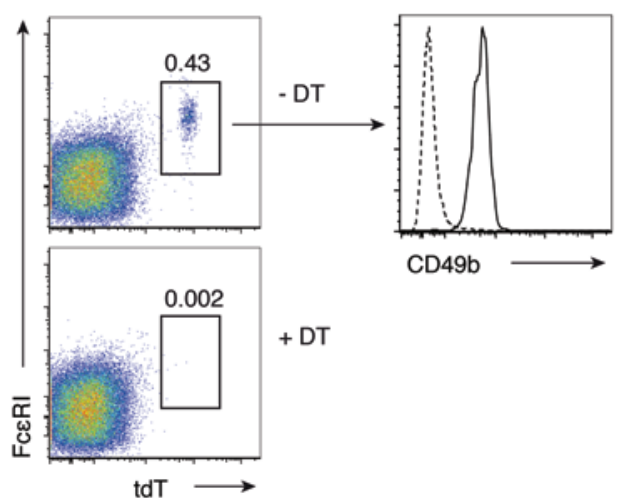

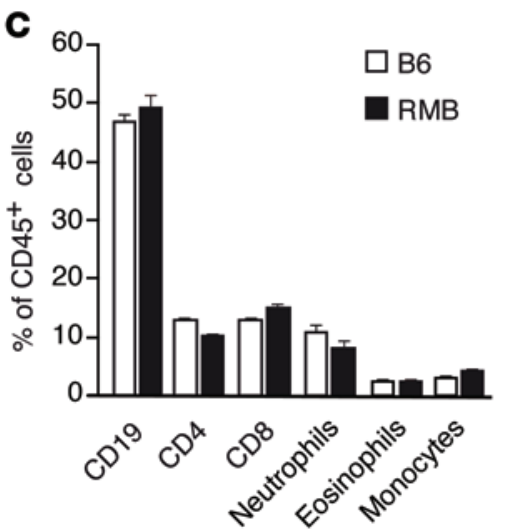

D Lymphocytes

Neutrophils

Monocytes

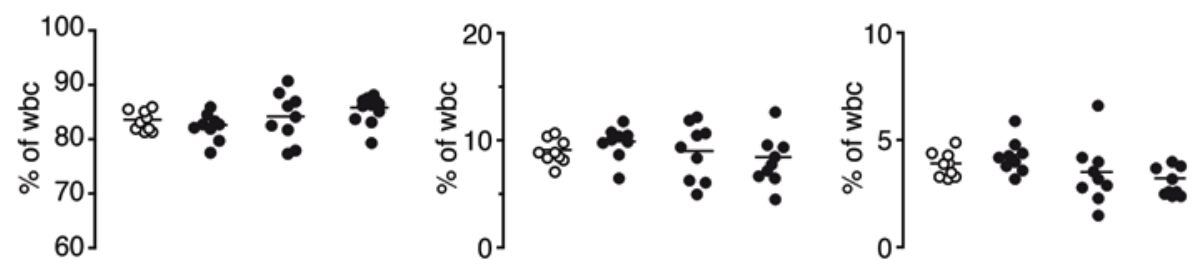

B6 RMB RMB RMB

B6 RMB RMB RMB

B6 RMB RMB RMB

DT - - 1 wk $3 w k$

DT - - $1 w k 3 w k$

DT - - 1 wk $3 w k$

Figure 1. Visualization and efficient depletion of mast cells and basophils in RMB mice. (A) Detection of mast cells (Fc\&RI+tdT+CD117+) by flow cytometry in the peritoneal cavity (left panel) and dermis (right panel) of RMB mice before and after 2 i.p. DT injections. (B) Detection of basophils (Fc\&RI ${ }^{+}$tdT $^{+}$CD496 ${ }^{+}$) in the blood (left panel) and in the spleen (right panel) of RMB mice before and after DT treatment. Dotted lines represent isotype control antibodies. Numbers in each panel represent the percentage of mast cells and basophils among CD45 gated cells. (C) Flow cytometric analysis of blood leukocytes in B6 and untreated RMB mice. Data represent the mean \pm SEM. (D) Percentage of blood lymphocytes, neutrophils, and monocytes in B6 and untreated RMB mice and in RMB mice 1 week or 3 weeks after DT treatment, as determined by a hematological analyzer ( $n=9$ mice/group). Data are representative of 5 independent experiments (A-C).

infection. This noxious effect is mediated by the release of preformed IL-4 as early as 15 minutes following the TLR4-dependent bacterial stimulation of mast cells. Our results demonstrate a novel functional crosstalk between PMCs and macrophages involving the immediate release of prestored IL- 4 by mast cells after bacterial exposure at the onset of infection, which has detrimental effects on survival in severe sepsis.

\section{Results}

Induced depletion of mast cells and basophils in red mast cell and basophil mice. The FceRI $\beta$ chain constitutes one of the signal-transducing subunits of the high-affinity receptor for IgE and is expressed specifically in mast cells and basophils in mice $(19,20)$. To assess the role of mast cells and/or basophils in inflammation, we generated a knock-in mouse model called the red mast cell and 
basophil (RMB) mouse. In these mice, the 3'-UTR of the Ms4a2 gene encoding the FceRI $\beta$ chain includes a cassette composed of an internal ribosomal entry site, a sequence coding for the bright red td-Tomato ( $t d \mathrm{~T}$ ) fluorescent protein, a 2A cleavage sequence, and the human diphtheria toxin receptor (hDTR) (Supplemental Figure 1; supplemental material available online with this article; doi:10.1172/JCI75212DS1). This allele allows mast cells and basophils to be tracked on the basis of their red fluorescence and confers sensitivity to diphtheria toxin (DT). To verify that mast cells in RMB mice were appropriately labeled and functional, we obtained bone marrow-derived mast cells (BMMCs) from these animals and compared their phenotype to those from WT C57Bl/6 (B6) mice. We found that all BMMCs from RMB mice were tdT-positive, expressed similar levels of mast cell surface markers (CD117 and FceRI), and displayed signaling capabilities identical to those of B6 BMMCs, as shown by ERK phosphorylation, calcium mobilization, and cellular degranulation (Supplemental Figure 2). Next, we analyzed different in vivo compartments for the presence of cells coexpressing tdT and FceRI. FceRI ${ }^{+} t^{-} T^{+}$mast cells constituted approximately $2 \%$ of cells in the peritoneal cavity and were all CD117 positive (Figure 1A). Similarly, all FceRI ${ }^{+} \mathrm{CD} 117^{+}$cells expressed tdT (Supplemental Figure 3A). Consistent with previous reports (21), the peritoneal cavity of 12 -week-old mice contained approximately $8 \times 10^{4} \mathrm{Fc}_{\mathrm{RRI}}{ }^{+} \mathrm{CD} 117^{+} \mathrm{tdT}^{+}$mast cells. Two i.p. injections of DT were sufficient to deplete within 2 days all mast cells present in the peritoneal cavity (Figure 1A). We observed a similar population of $\mathrm{Fc}_{\mathrm{R}} \mathrm{RI}^{+} \mathrm{CD} 117^{+} \mathrm{tdT}^{+}$mast cells in the skin, and 2 injections of DT led to their complete depletion as well (Figure 1A). In contrast, the FceRI'tdT $\mathrm{T}^{+}$cells found in the blood and spleen were CD117 ${ }^{-}$but expressed high levels of CD49b, indicating that they corresponded to basophils (Figure 1B and Supplemental Figure 3B). Again, 2 injections of DT were sufficient to completely eliminate basophils from these compartments (Figure 1B).

Several mouse models deprived of mast cells or basophils have been reported. Some of them, notably those relying on mutations in the Kit locus, display an aberrant hematopoietic compartment, precluding a proper analysis of the role of mast cells in inflammatory diseases (Supplemental Figure 4 and ref. 22). We therefore assessed the numbers of various white blood cell populations in RMB mice to assess changes at the hematopoietic level. An analysis of $\mathrm{CD} 45^{+}$cells from the blood of RMB and B6 mice showed comparable numbers of neutrophils, eosinophils, monocytes, and $\mathrm{B}$ and $\mathrm{T}$ cells (Figure 1C). Furthermore, DT treatment of RMB mice did not affect the percentage of lymphocytes, neutrophils, or monocytes (Figure 1D). Altogether, these data suggest that the RMB mouse model permits the efficient identification and depletion of both mast cells and basophils, without inducing any adventitious hematopoietic abnormalities.

Fast repopulation of basophils compared with mast cells. As shown above, DT injection into RMB mice simultaneously ablated all mast cell and basophil populations. This allowed us to simultaneously assess the repopulation kinetics of mast cells and basophils. While their numbers remained low, some blood basophils reappeared on day 6 after DT treatment, and they were completely replenished by day 12 (Figure $2 \mathrm{~A}$ ). In contrast, no significant repopulation of PMCs was detected by days 6 or 12 (Figure 2B). Even 2 months after DT injection, less than $6 \%$ of mast cells had repopulated the peritoneum of RMB mice, and 6 months after DT treatment, mast cells only reached half their normal levels (Figure 2C). To evaluate the role of mast cells in vivo, we induced IgE-triggered passive systemic anaphylaxis (PSA) on day 12 after DT treatment. The absence of mast cells alone (i.e., after basophil repopulation) in RMB mice was sufficient to render them resistant to the PSA-induced temperature drop, emphasizing the role of these cells in IgE-mediated PSA (Figure 2D). Together, these results show that basophils and PMCs exhibit different repopulation kinetics in RMB mice following ablation with DT, allowing us to determine the appropriate time window in which to analyze the physiological role of mast cells independently of basophils. Therefore, these "mast cell-depleted-only" mice can be used to specifically investigate the physiological role of mast cells in the absence of alteration of other immune cells including basophils.

Detrimental role of mast cells in acute sepsis. Next, we used our DT-treated RMB mice to investigate the role of resident PMCs in CLP, an acute inflammatory model of sepsis. Severe CLP was induced according to our previously established protocol $(23,24)$ and led to a survival rate of approximately $10 \%$ in control RMB mice 48 hours after induction (Figure 3A). In contrast, DT-treated RMB mice showed a higher survival rate, with almost $40 \%$ of mice still alive at the end of the examination period (Figure 3A, left panel). DT injections alone did not affect the overall survival rate of $\mathrm{B} 6$ mice, as they showed an identical survival rate to that of PBS-injected B6 mice (Figure 3A, right panel).

Mortality in sepsis results from multiorgan failure due to uncontrolled bacterial proliferation and dissemination as well as the excessive production of proinflammatory cytokines (25). Accordingly, chemokines and cytokines such as MCP-1, IFN- $\gamma$, IL-6, and TNF were elevated at 6, 12, 18, and 24 hours after CLP induction. However, we observed no difference in these levels between PBS- and DT-treated RMB mice (Figure 3B). We next checked for the presence of bacteria in the peritoneum and serum of PBS- and DT-treated RMB mice. As early as 6 hours after CLP induction, the level of bacteria detected in peritoneal lavage was markedly lower in mast cell-depleted RMB mice than in control RMB mice (Figure 3C, left panel). Likewise, 18 hours after CLP induction, bacteremia was considerably lower in mast celldepleted RMB mice than in control RMB mice (Figure 3C, right panel). Furthermore, we observed no difference in mortality between PBS- and DT-treated mice in the sepsis model induced by injection of LPS, emphasizing that the increased survival rate of mast cell-depleted mice is dependent on the bacterial burden (Supplemental Figure 5). These results indicate that mast cells play a detrimental role in severe sepsis by preventing the efficient control of bacterial dissemination.

Mast cells affect resident macrophage levels during sepsis. The increased presence of bacteria suggested a possible deficit in immune effector cell function. Resident peritoneal macrophages have been proposed to play an important role in the control of sepsis $(8,9)$. Therefore, before inducing sepsis, we first analyzed whether injection of DT into the peritoneal cavity affects resident cell populations. We noted no difference in the number of resident macrophages $\left(\mathrm{Ly} 6 \mathrm{C}^{\mathrm{lo}} \mathrm{F} 4 / 80^{+}\right)$, eosinophils, B cells, or $\mathrm{T}$ cells in DT-treated RMB mice as compared with the numbers detected in their PBS-treated or untreated counterparts or control 
A

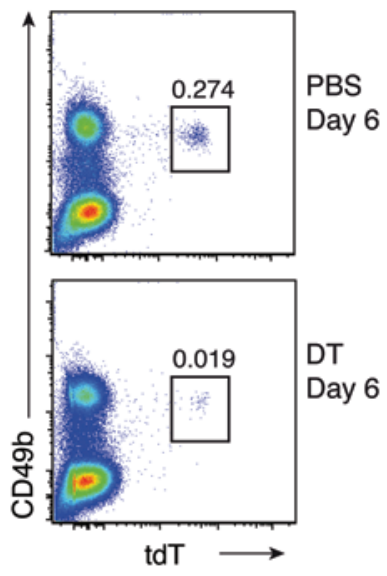

B

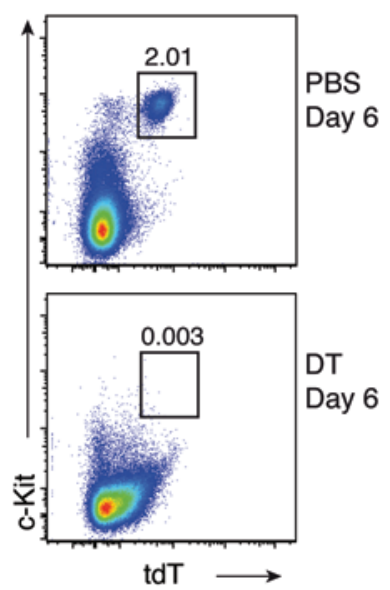

C

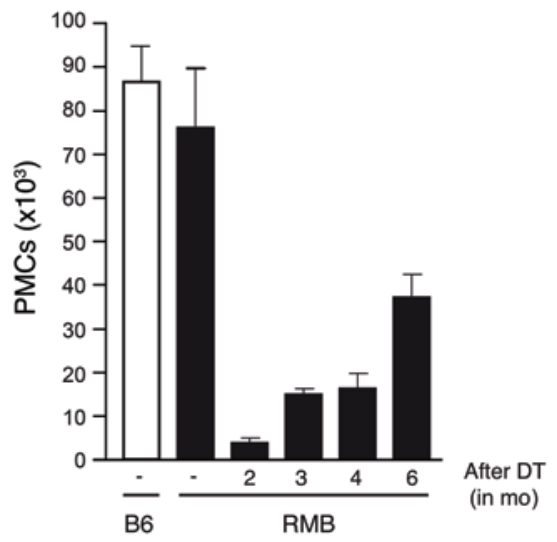

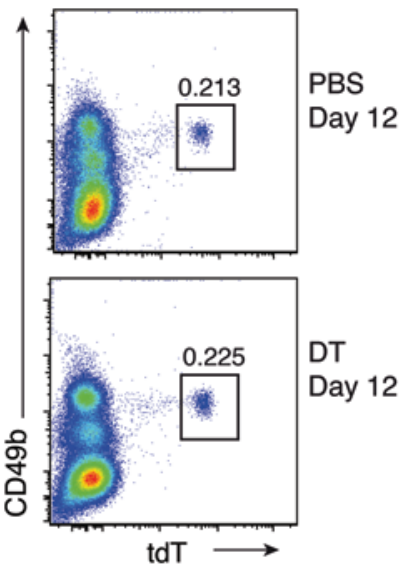

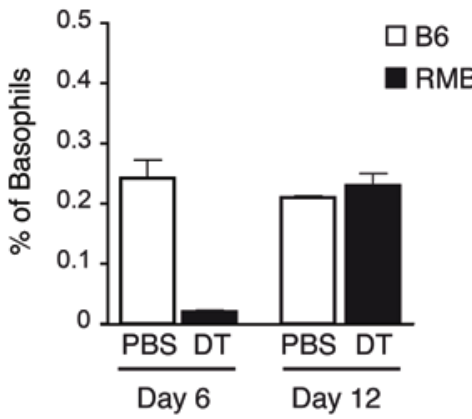

PBS

Day 12

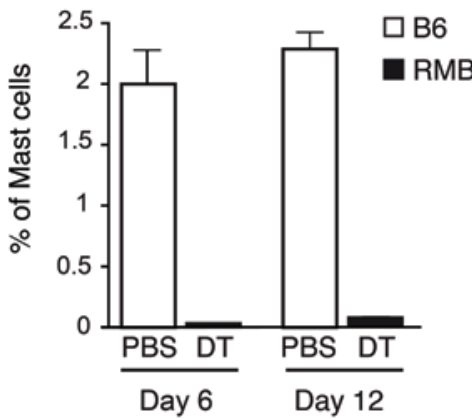

Figure 2. Differential repopulation kinetics of mast cells and basophils after DT depletion. (A and B) Flow cytometric analysis of blood basophils $\left(\mathrm{CD}{ }^{+} \mathrm{tdT}^{+}\right)(\mathbf{A})$ and PMCs (CD117 $\left.\mathrm{tdT}^{+}\right)(\mathbf{B})$ at 6 and 12 days after DT injection. Numbers in each panel correspond to the percentage of basophils or mast cells among CD45+ cells. (C) Analysis of PMCs (FcERI +tdT + CD117+) in RMB mice 2, 3, 4, and 6 months after DT injection as compared with those from untreated RMB and B6 mice ( $n=4$ mice/group). (D) Temperature was monitored every 10 minutes after the induction of passive systemic anaphylaxis in RMB mice injected with PBS (black circles) or DT (dark gray circles) as well as in B6 mice injected with PBS (light gray circles) or DT (white circles). $n=5$ mice/group. Data are representative of 5 independent experiments and represent the mean \pm SEM.

B6 mice (Figure 4A). Next, we investigated how the induction of the CLP procedure affected resident and infiltrating cell populations. Remarkably, resident macrophage numbers rapidly decreased in DT-treated RMB mice when compared with those in PBS-treated RMB mice during the early stages of infection, at 6 and 12 hours (Figure 4, B and C), while the numbers of B cells remained unaffected by DT treatment (Figure 4D). Of note, peritoneal macrophages as well as NK, NKT, and ILC2 were not sensitive to DT, unlike BMMCs (Supplemental Figure 6, A-C). With respect to the numbers of infiltrating cells such as inflammatory monocytes or neutrophils, we found no difference between those in DT- and PBS-treated RMB mice (Figure 4, E and F). 
A

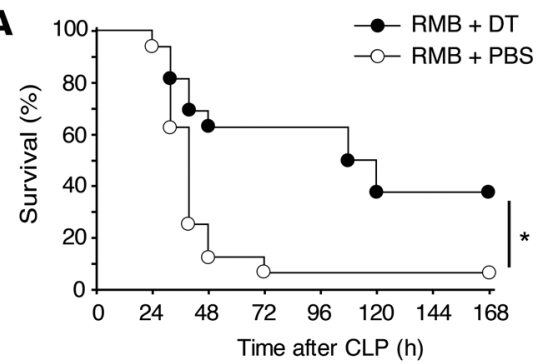

B
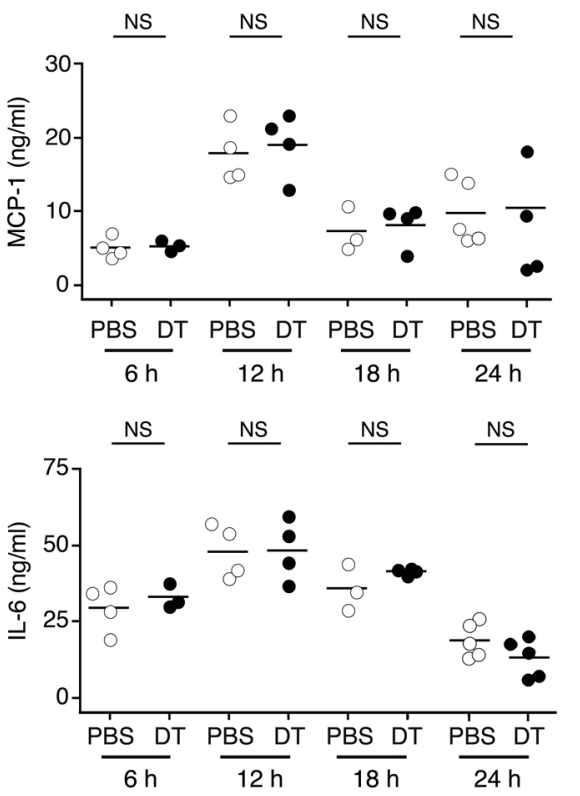
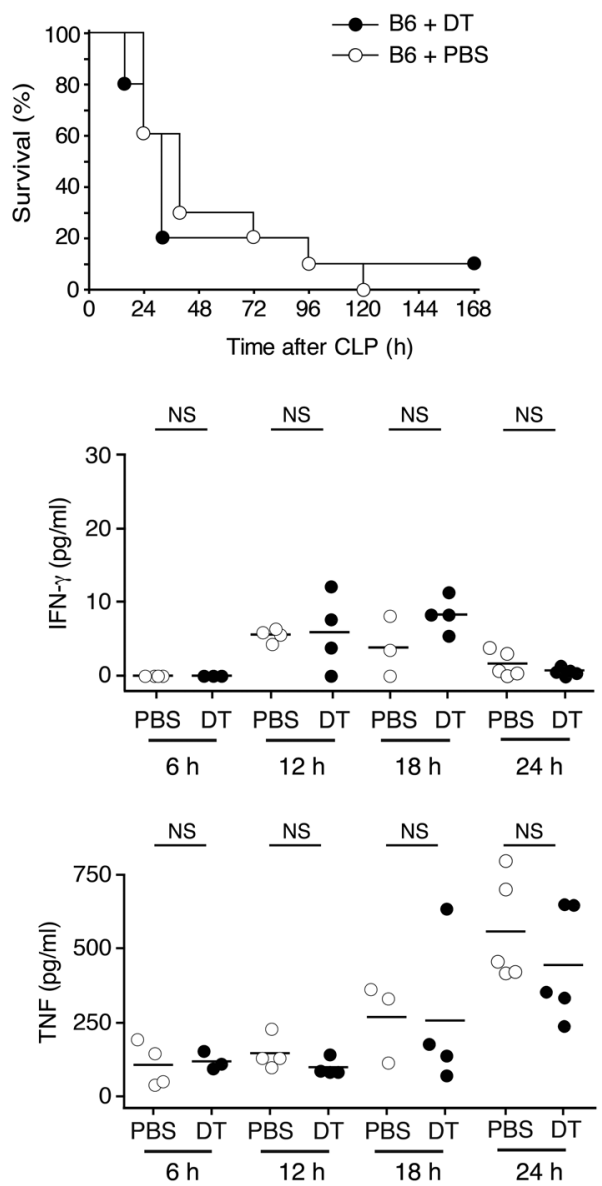

Figure 3. Mast cells aggravate severe sepsis.

(A) Left panel: Survival after acute CLP in PBS-injected (white circles; $n=16$ ) and DT-treated RMB mice (black circles; $n=16$ ). Kaplan-Meier curves and the log-rank test were used to analyze mortality rates. ${ }^{*} P=0.0282$. Right panel: Survival after acute CLP in PBS-injected (white circles; $n=10$ ) and DT-injected B6 mice (black circles; $n=10)$. (B) Concentration of the proinflammatory cytokines MCP-1, IFN- $\gamma$, IL-6, and TNF in the peritoneal cavity at $6,12,18$, and 24 hours after CLP in RMB mice injected with either PBS (white circles) or DT (black circles). Each circle represents a single mouse; small horizontal lines indicate the mean of all mice per condition. (C) Bacterial numbers (CFU) in the peritoneal fluid (left panel) and serum (right panel) of PBS-injected (white bars) or DT-treated RMB mice (black bars) 6 and 18 hours after CLP. Data are representative of 6 independent experiments. Values obtained from 6 mice per group. NS, not statistically different. ${ }^{*} P<0.05$; ${ }^{* *} P<0.01$. Data represent the mean \pm SEM.
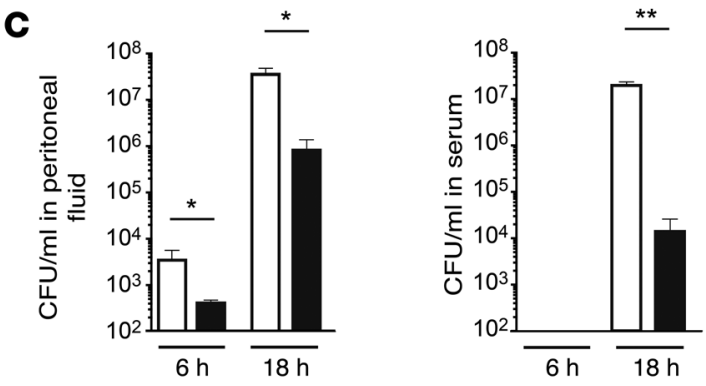

$\square \mathrm{RMB}+\mathrm{PBS}$
$\mathrm{RMB}+\mathrm{DT}$

Taken together, these results suggest that mast cells play an important role during the early stages of sepsis by controlling resident macrophage numbers rather than affecting the recruitment of inflammatory cells.

Mast cells rapidly regulate phagocytosis of $E$. coli by peritoneal macrophages. We have shown above that the absence of mast cells correlates with lower bacteremia and the early disappearance of resident macrophages. Macrophage disappearance is known to be a marker of their activity following peritoneal infection $(26,27)$. We therefore hypothesized that mast cells directly affect resident macrophage function by controlling their phagocytic activity during the early stages of infection. To test this hypothesis, we injected FITC-labeled $E$. coli bacteria into the peritoneal cavity of DT- or PBS-treated RMB mice. After 15 minutes, mice were sacrificed, and resident peritoneal macrophages were analyzed for their phagocytic activity by monitoring their shift in FITC fluorescence. Mast cell-depleted mice presented markedly higher peritoneal macrophage phagocytosis than did PBS-injected control mice (Figure 5A, upper panel). Likewise, mast cell-deficient $\mathrm{Kit}^{\mathrm{W}-\mathrm{sh} / \mathrm{W}-\mathrm{sh}}$ mice exhibited higher macrophage phagocytosis than did B6 mice (Figure 5A, lower panel). These results indicate that the absence of mast cells either in DT-treated RMB or $\mathrm{Kit}^{\mathrm{W-sh} / \mathrm{W}-\mathrm{sh}}$ mice is associated with enhanced phagocytic activity by resident macrophages. We next assessed whether this inhibitory effect on macrophage phagocytosis was due to the release of soluble factors by mast cells. BMMCs were stimulated with LPS or fixed bacteria for 2 hours, and cell-free supernatants were transferred onto B6 peritoneal macrophages, selected by adherence, in the presence of FITC-labeled E. coli to follow macrophage phagocytic activity. We noted an inhibition of macrophage phagocytosis with supernatants of mast cells stimulated with either LPS or bacteria (Figure $5 \mathrm{~B}$ ). 


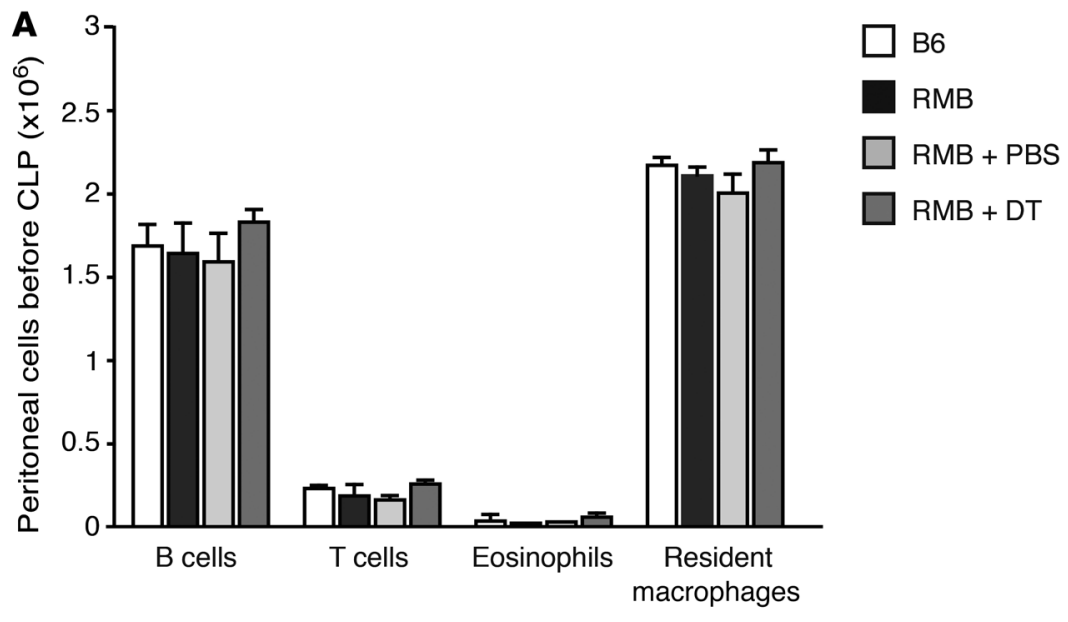

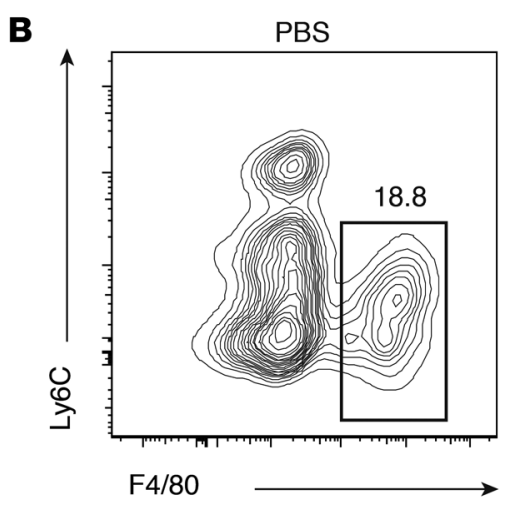

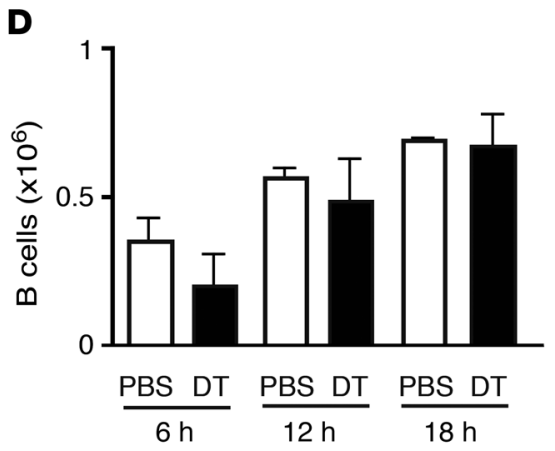

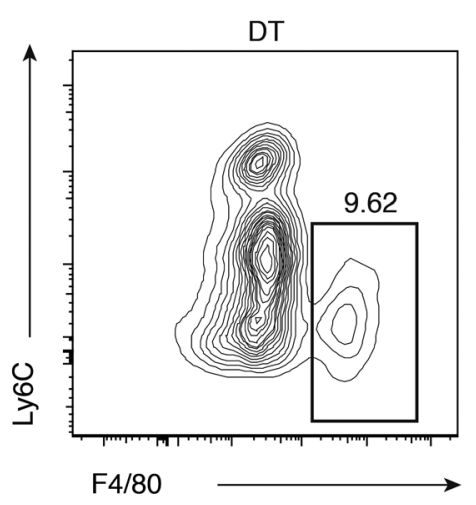

$\mathbf{E}$

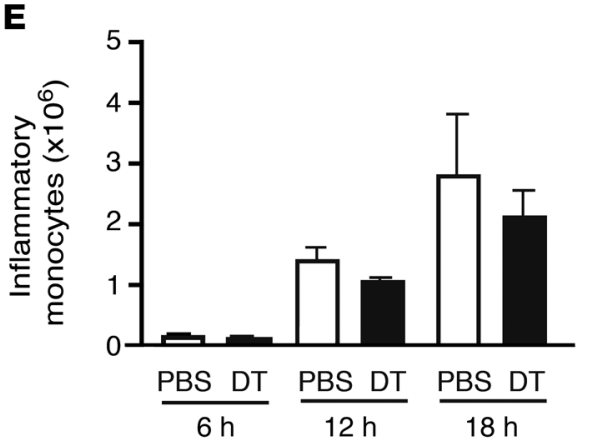

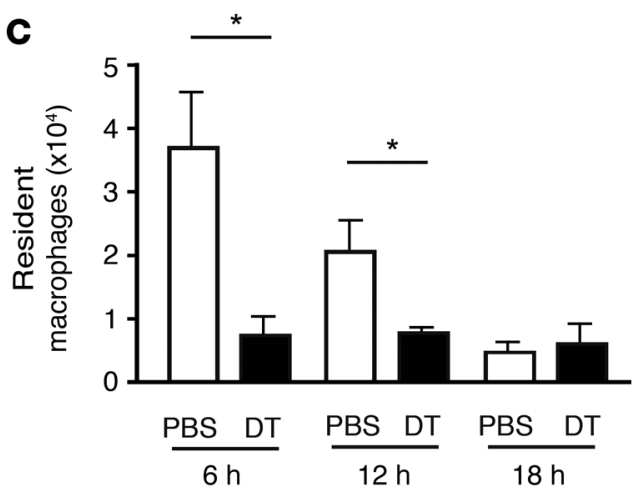

$\mathbf{F}$

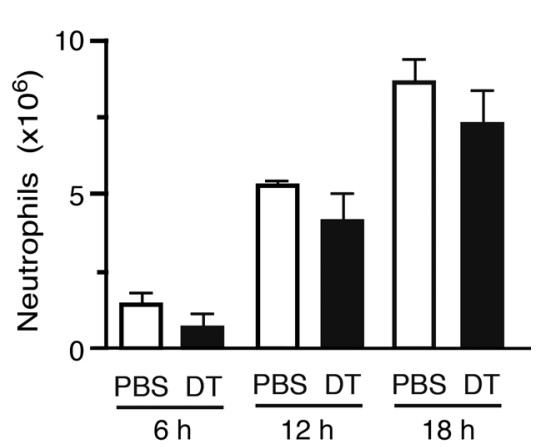

Figure 4. Decrease in resident macrophage numbers in mast cell-deficient mice after sepsis. (A) Identical levels of resident macrophages, $T$ and $B$ lymphocytes, as well as eosinophils in B6, RMB, and PBS- or DT-treated RMB mice before CLP determined by flow cytometric analysis. (B and C) Labeling profiles of resident macrophages in DT- and PBS-treated mice 6 hours after CLP (B) and absolute numbers at 6, 12, and 18 hours after CLP (C). Numbers above gated areas in $\mathbf{B}$ indicate the percentage of macrophages among CD45+ cells. (D-F) Flow cytometric analysis of B cells (D), inflammatory monocytes (E), and neutrophils (F) in the peritoneum at 6, 12, and 18 hours after CLP in PBS-injected (white bars) and DT-treated RMB mice (black bars). Data are representative of 5 independent experiments and represent the mean \pm SEM. ${ }^{*} P<0.05$.

Inhibition of macrophage phagocytosis by mast cells involves TLR4-mediated activation. We next attempted to further characterize the inhibition of macrophage phagocytosis by mast cells by developing an assay to specifically quantify the level of bacteria internalized within macrophages and used pHrodo E. coli, which turns fluorescent upon phagosome acidification. An analysis of kinetics revealed that mast cell supernatants collected as early as 15 minutes after bacterial stimulation significantly inhibited macrophage phagocytosis, while supernatants from unstimulated BMMCs did not (Figure 6A). Using confocal microscopic analysis, we confirmed the rapid inhibitory effect of mast cells on phagocytosis in vivo in macrophages from PBS-or DT-treated mice 15 minutes after pHrodo E. coli injection (Figure 6B). Notably, in the absence of mast cell supernatant, macrophages isolated from the peritoneal cavity of both DT- and PBS-treated RMB mice presented the same phagocytic capacity and displayed identical phagosomal acidification (Supplemental Figure 7). Since stimulation with both LPS and bacteria was able to induce the production of inhibitory soluble factors, we examined whether this process involved TLR signaling in mast cells. Cell-free supernatants from 
A
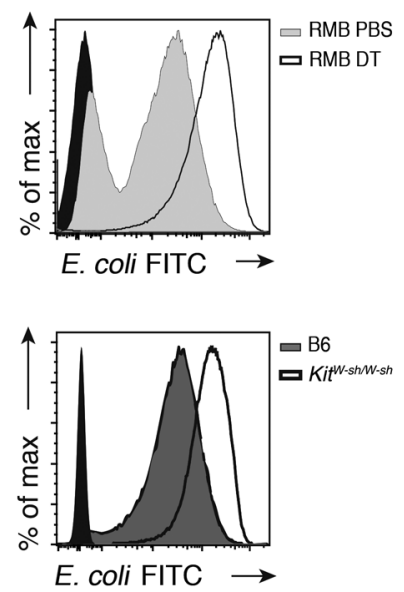

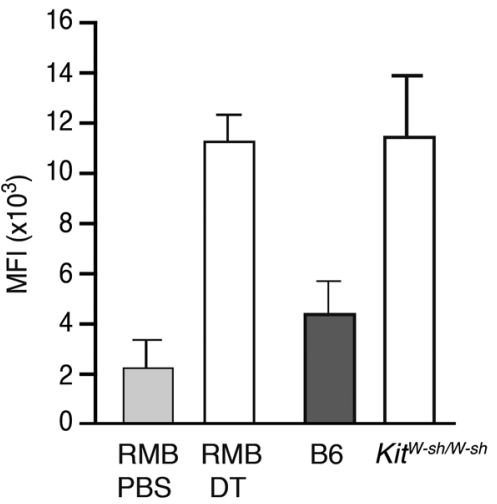

B
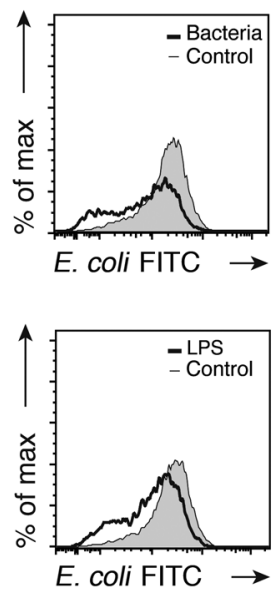

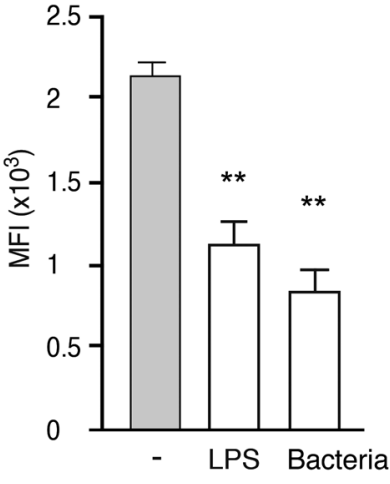

Figure 5. Rapid regulation of macrophage phagocytosis by mast cells. (A) Flow cytometric analysis of in vivo peritoneal macrophage phagocytosis of FITC-labeled E. coli injected into RMB mice previously treated with PBS or DT (upper panel) and into B6 or Kit ${ }^{W-s h / W-s h}$ mice (lower panel). Black histogram represents resident macrophages without $E$. coli-FITC injection. (B) Flow cytometric analysis of ex vivo peritoneal macrophage phagocytosis of $E$. coli-FITC in the presence of cell-free supernatants from BMMCs activated either by LPS or E. coli-FITC (Bacteria). ${ }^{* *} P<0.01$. Data are representative of 3 independent experiments and represent the mean \pm SEM.

BMMCs derived from mice deficient in either TLR4 or its downstream adaptor protein MyD88 (for phenotyping see Supplemental Figure 8) and stimulated with bacteria did not impair macrophage phagocytosis, confirming that the observed inhibition required the activation of mast cells through the TLR4 signaling pathway (Figure 6C). Notably, BMMCs from B6 and RMB mice activated with bacteria inhibited macrophage phagocytosis to a similar extent (Figure 6C), and inhibitory activity was also observed with stimulated peritoneal-derived mast cells (PDMCs) (Figure 6D), emphasizing that both BMMCs and PDMCs are capable of inhibiting macrophage phagocytosis following bacterial triggering.

Mast cell-derived IL-4 controls phagocytosis by peritoneal macrophages. We next attempted to identify the type of soluble factor that regulates macrophage phagocytosis. Mast cells can rapidly release a number of cytokines upon stimulation. In particular, they produce substantial amounts of Il4 mRNA (http://biogps.org/\#goto= genereport\&id=16189) and proteins reported to be prestored in cytoplasmic granules (28-30). Since IL-4 has been suggested to inhibit the phagocytosis of pathogens by macrophages (31), we assessed the role of mast cell-derived IL- 4 in the regulation of peritoneal macrophage phagocytosis. Bacterial triggering induced the rapid release of IL-4, which was already apparent within 15 minutes after addition of the stimulus (Figure 7A). The preincubation of peritoneal macrophages with recombinant IL-4 inhibited their phagocytosis of pHrodo E. coli in a dose-dependent manner (Figure 7B). To examine the involvement of mast cell-derived IL-4 in this inhibition of phagocytosis, we used an IL-4-neutralizing antibody. The inhibitory effect of cell-free supernatants obtained from bacteria-stimulated BMMCs on macrophage phagocytosis was abrogated by the addition of the IL-4-neutralizing antibody, as compared with that observed with a control antibody (Figure 7C). Likewise, supernatants obtained from BMMCs from IL-4-deficient mice failed to inhibit the phagocytosis of $E$. coli by macrophages, while supernatants from BMMCs from TNF-deficient mice as well as from RMB BMMCs demonstrated a strong inhibitory effect (Fig- ure 7D). Furthermore, macrophages deficient in the $\alpha$ chain of the IL-4 receptor (IL-4R $\alpha$ ) were no longer susceptible to the inhibitory signal, confirming that the inhibitory effect was due to IL-4R signaling (Figure 7E). As BMMCs also produce IL-13, which is known to bind to the IL-4R $\alpha$ chain (32), we analyzed the possible involvement of IL-13 in the inhibition of macrophage phagocytosis. In contrast to the IL-4-neutralizing antibody, the addition of an IL-13neutralizing antibody to supernatants from bacteria-stimulated BMMCs failed to abrogate their inhibitory effect on macrophage phagocytosis. Furthermore, supernatants collected from BMMCs from IL-13-deficient mice after bacterial stimulation were still able to inhibit phagocytosis (Figure $7 F$ ). These experiments strongly support the specific role of mast cell-derived IL-4 in the inhibition of macrophage phagocytosis.

Survival of septic mice is impaired by mast cell $I L-4$ and can be restored by anti-IL-4 treatment. Finally, we assessed the role of mast cell-derived IL-4 in vivo in the control of severe sepsis and the potential effects of treatment with an IL-4-neutralizing antibody. First, BMMCs from IL-4-deficient mice were used to repopulate RMB mice previously depleted of endogenous mast cells following DT treatment (Supplemental Figure 9). Mice were then assessed for survival after the induction of CLP. Mice repopulated with B6 mast cells showed decreased survival as compared with mice repopulated with IL-4-deficient BMMCs (Figure 8A), corroborating the role of mast cell-derived IL-4 in the control of sepsis in vivo. To further confirm the key role of IL-4, we next asked whether treatment with an anti-IL-4 antibody might improve the survival of septic mice. The administration of an IL-4-neutralizing antibody (10 $\mu \mathrm{g}$ per mouse) to B6 mice during CLP surgery, just before wound closure, led to increased survival when compared with treatment using control IgG (Figure 8B). Collectively, these results suggest that IL-4 secreted by bacteria-stimulated mast cells impairs resident macrophage phagocytosis, accounting for the increased mast cell-dependent mortality observed in severe sepsis (Supplemental Figure 10). 
A

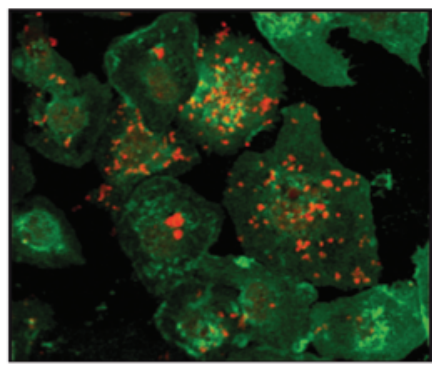

- BMMC supernatants

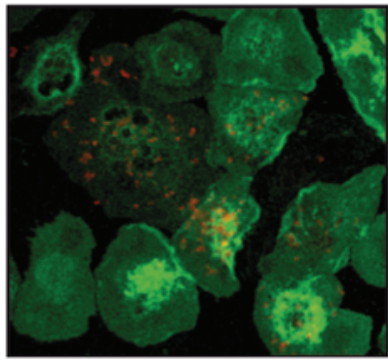

+ BMMC supernatants
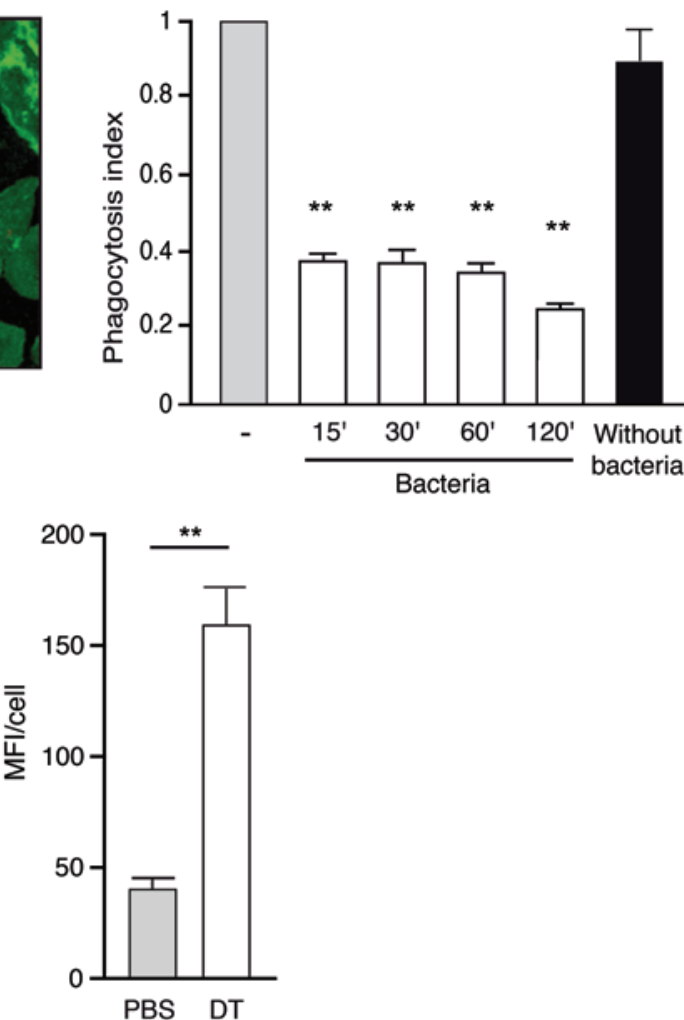

PBS DT
C

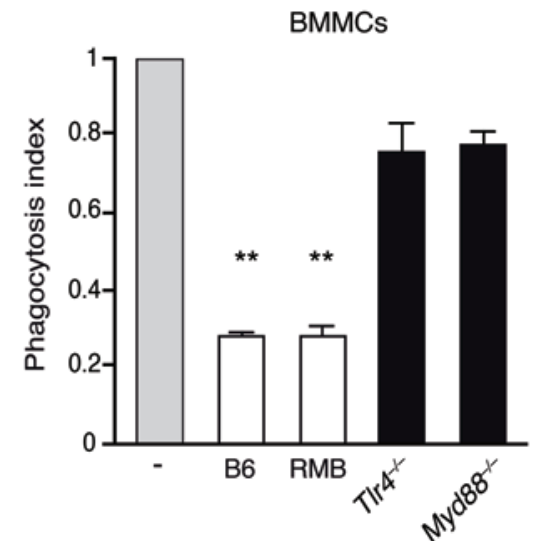

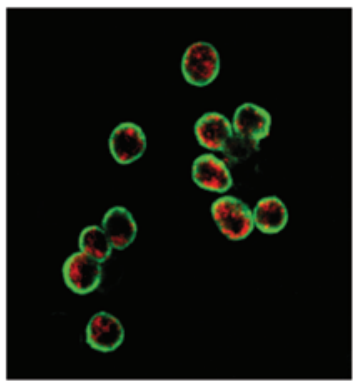

DT
D

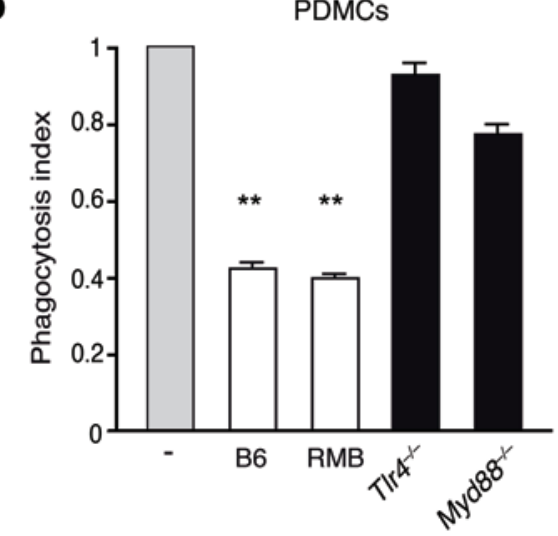

Figure 6. Macrophage phagocytosis inhibition by mast cells is dependent on TLR4. (A) Representative confocal microscopic analysis of in vitro peritoneal macrophage phagocytosis of pHrodo E. coli (in red) after the addition (+ BMMC supernatants) or not (- BMMC supernatants) of cell-free supernatants from BMMCs activated for 15 minutes with fixed bacteria. Right: Histograms show inhibition of macrophage phagocytosis by supernatants of unstimulated (Without bacteria) BMMCs or BMMCs activated for 15, 30, 60, or 120 minutes with fixed bacteria. (B) Representative confocal analysis of in vivo peritoneal macrophage phagocytosis of pHrodo E. coli (in red) injected for 15 minutes into the peritoneal cavity of PBS- or DT-treated RMB mice. Cells from the peritoneal cavity were collected and subjected to a cytospin protocol before labeling. (C and $\mathbf{D})$ In vitro peritoneal macrophage phagocytosis of pHrodo $E$. coli in the presence of supernatants from BMMCs (C) or PDMCs (D) derived from B6, RMB, TIr4 ${ }^{-/-}$, and Myd88 $8^{-/-}$mice activated with fixed bacteria and assessed by confocal microscopy. Data are representative of 4 independent experiments and represent the mean $\pm \mathrm{SEM} .{ }^{* *} P<0.01$.

\section{Discussion}

In addition to their well-known functions in IgE-mediated allergies and worm infections, mast cells are now viewed as highly versatile inflammatory cells that play important roles in many pathologies. They can be stimulated by numerous cytokines and neuropeptides as well as by pathogens including viruses and bacteria (33). In the present study, we developed a novel mast cell-deficient mouse model called the RMB mouse that, in contrast to Kit-dependent models, does not bear hematological abnormalities. Using these
RMB mice, we show that mast cells are detrimental to survival in a severe sepsis model. This effect involves the rapid E. coli-mediated release of the Th2 cytokine IL-4 by PMCs, which dampens phagocytosis by resident macrophages. Previous studies indicated that mast cell responses to bacterial infection can vary depending on the type of pathogen, the site of infection, and the sensitization state of the mast cells (34). Recent data have shown that bacterial products such as $S$. aureus $\Delta$-toxin can be a potent inducer of mast cell degranulation (35), while secreted Salmonella protein tyrosine phosphatase 
A
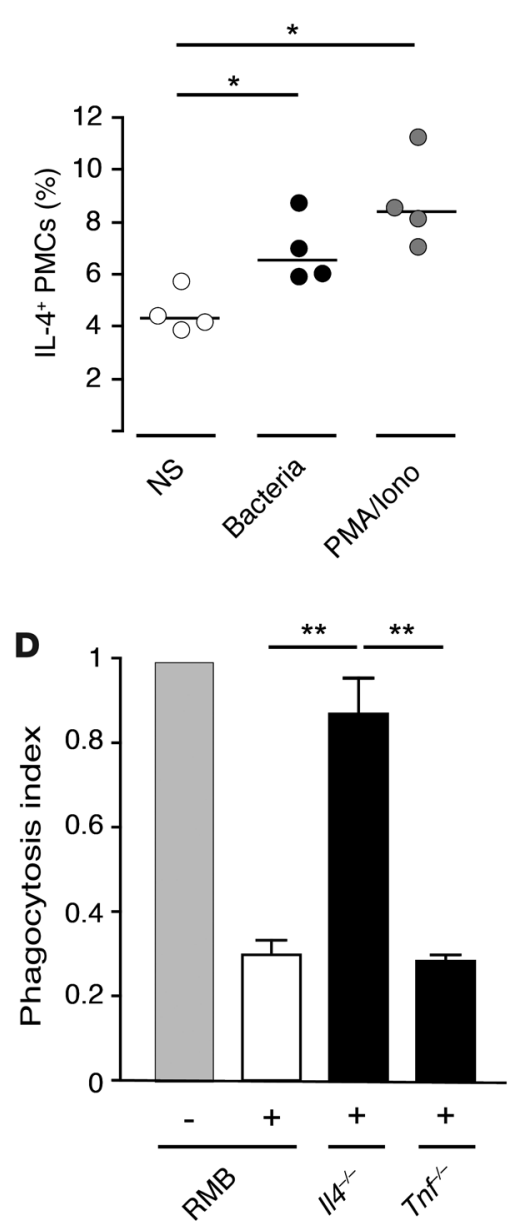

B

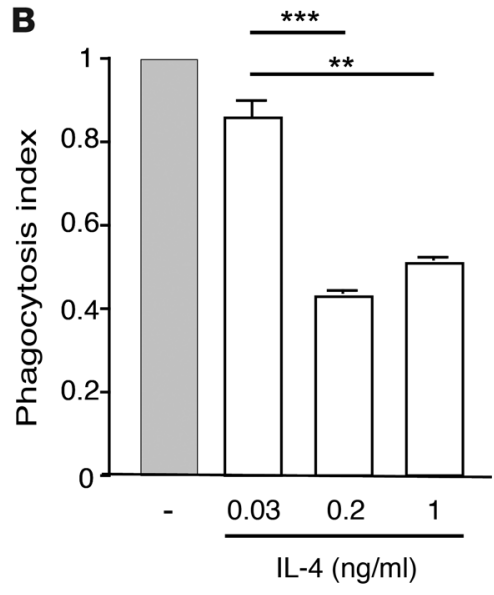

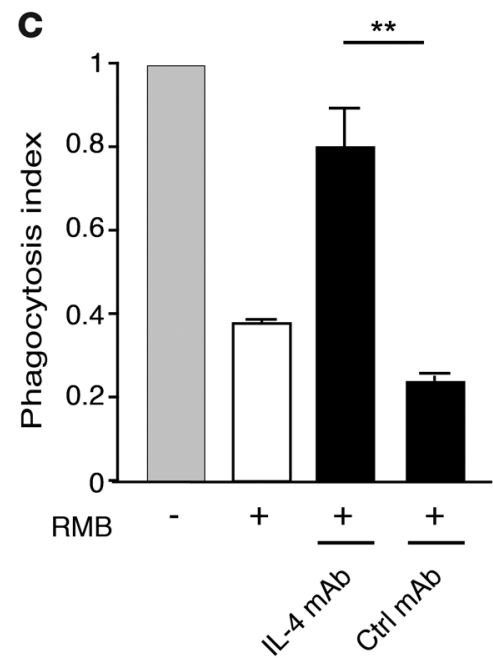

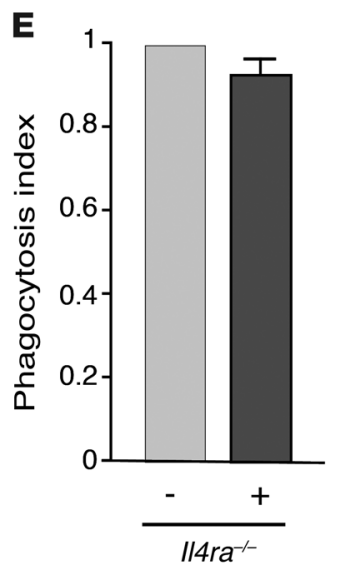

$\mathbf{F}$

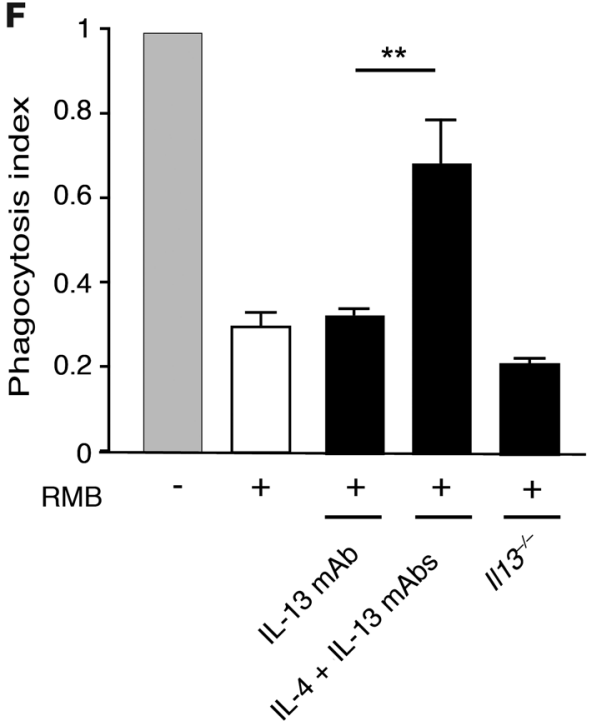

Figure 7. IL-4 released from mast cells decreases macrophage phagocytosis. (A) IL-4 from PMCs before (white circles) and after a 15-minute stimulation with bacteria (black circles) or PMA/ionomycin (gray circles). NS, not stimulated. Each circle represents an individual experiment; small horizontal lines indicate the mean of 4 independent experiments. ${ }^{*} P<0.05$. (B) Peritoneal macrophage phagocytosis of pHrodo $E$. coli in the presence of different doses of recombinant IL-4. ${ }^{* *} P<0.01 ;{ }^{* *} P<0.001$. (C) Peritoneal macrophage phagocytosis of pHrodo $E$. coli in the presence of cell-free supernatants from BMMCs activated by fixed bacteria and preincubated with anti-IL-4-blocking antibody or isotype control IgC antibody. ${ }^{* *} P<0.01$. (D) Peritoneal macrophage phagocytosis of pHrodo $E$. coli in the presence of supernatants from RMB-derived BMMCs derived from RMB, $114^{-1-}$, or $T \mathrm{Tf}^{-/-}$mice activated with fixed bacteria. ${ }^{* *} P<0.01$. (E) Phagocytosis of pHrodo E. coli by II4ra-deficient peritoneal macrophage in the presence of cell-free supernatants from RMB BMMCs activated by fixed bacteria. (F) Peritoneal macrophage phagocytosis of pHrodo $E$. coli in the presence of cell-free supernatants from RMB BMMCs activated by fixed bacteria and preincubated with anti-IL-13 or anti-IL-13 plus anti-IL-4-blocking antibodies and bacteria-activated supernatants from $1 / 13^{-/-}$BMMCs. Data are representative of $4(\mathbf{A})$ and $3(\mathbf{B}-\mathbf{F})$ independent experiments and represent the mean $\pm \mathrm{SEM}$. ${ }^{* *} P<0.01 ;{ }^{* *} P<0.001$.

(SptP) of S. typhimurium, a structural homolog of Yersinia YopH, suppresses degranulation of skin mast cells (36). Furthermore, the heterogeneity of mast cells in various tissues may also represent an important factor determining disease development (5).

Until recently, studies of the role of mast cells in vivo relied on $\mathrm{Kit}^{\mathrm{W} / \mathrm{W}-v}$ or $\mathrm{Kit}^{\mathrm{W}-\mathrm{s} / \mathrm{W}-\mathrm{sh}}$ mice, both of which harbor Kit mutations (10-17). These mice exhibit a profound defect in mast cell development, but also bear other Kit-related abnormalities including anemia, neutropenia, or neutrophilia. This limits their use in the analysis of acute inflammatory conditions that involve other innate immune cells. Although mast cells can be reintroduced into $\mathrm{Kit}^{\mathrm{W} / \mathrm{W}-\mathrm{v}}$ or $\mathrm{Kit}^{\mathrm{W}-\mathrm{s} h / \mathrm{W}-\mathrm{sh}}$ mice to restore function, such reconstitution does not yield exactly the same distribution as that seen in WT mice $(37,38)$. New mast cell-deficient strains independent of Kit have thus been generated. These include the Mcpt5-Cre ${ }^{+} \mathrm{iDTR}^{+}$ mice, in which Cre expression under the control of the mast cell protease 5 promoter is combined with the $I D T R$ line to evaluate the role of mast cells in dinitrofluorobenzene-induced (DNFBinduced) contact hypersensitivity (39). In $\mathrm{Cpa}^{\mathrm{Cre} /+}$ mice, mast cells are absent due to the insertion of Cre recombinase under the carboxypeptidase $\mathrm{A} 3$ promoter, and in contrast to $\mathrm{Kit}^{\mathrm{W} / \mathrm{W}-\mathrm{v}}$ mice, they retain susceptibility to autoimmune arthritis (40). However, these mice bear other alterations such as a partial reduction in

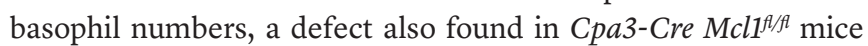



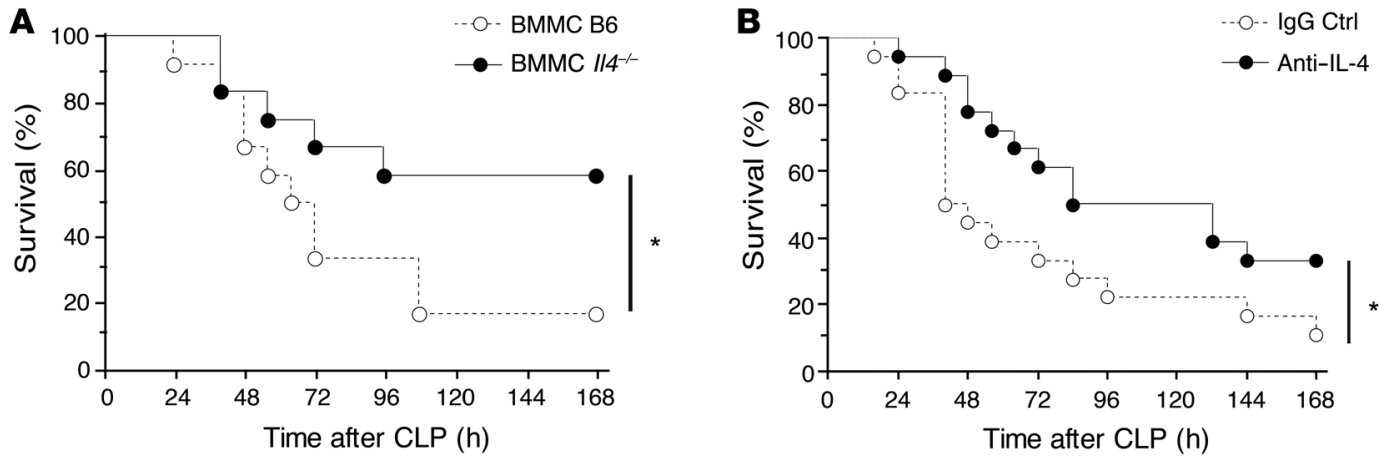

Figure 8. Mast cells mediate IL-4-impeded survival in severe sepsis. (A) Survival of DT-treated RMB mice reconstituted with BMMCs from B6 mice (white circles; $n=12$ ) or with BMMCs from IL-4-deficient mice (black circles; $n=12$ ) after acute CLP. ${ }^{*} P<0.05$. (B) Survival of RMB mice injected with anti-IL-4 antibody (black circles; $n=18$ ) and isotype control IgG (white circles; $n=18$ ) after acute CLP. ${ }^{*} P<0.05$.

(41). Although in our RMB model, both basophils and mast cells are deleted after DT injections, the fact that basophils are fully reconstituted 12 days after DT treatment, whereas mast cells are still absent, allows the selective assessment of the role of mast cells in various pathological situations.

To address the interaction of mast cells with other tissue-resident cells in bacterial infection, we used a severe model of septic peritonitis (high-grade sepsis). In this setting of massive bacterial infection, the kinetics of the immune response via resident peritoneal cells is believed to be crucial to contain the spread of the infection $(8,23)$. In the peritoneal cavity in steady state, the number of resident macrophages is 20 times higher than that of mast cells, which represent only about $2 \%$ of resident cells. Although mast cells may also be capable of phagocytosing bacteria (42), in the case of severe sepsis, the initial killing of bacteria appears to be carried out by peritoneal macrophages. Indeed, our data show that as early as 15 minutes after the injection of fluorescent bacteria into the peritoneal cavity, these were mostly found to be ingested by resident macrophages. Strikingly, our experiments demonstrate that this bactericidal activity of macrophages was diminished in PBS-treated RMB mice, supporting an aggravating role of mast cells in sepsis.

Mast cells are known for their ability to release numerous inflammatory products capable of controlling their cellular environment. Indeed, mast cells can quickly release proinflammatory cytokines such as TNF and IL-6, both of which are central effectors involved in monocyte and macrophage activation and the local recruitment of neutrophils (43). However, these 2 cytokines are also secreted in large quantities by peritoneal macrophages, which vastly outnumber mast cells and can be quickly released after TLR activation $(44,45)$. This may explain why we did not detect any major difference in either TNF or IL- 6 levels between mast cell-deficient and control RMB mice after CLP (46).

Our results indicate that mast cell control over resident macrophage phagocytosis is mediated by IL-4. Under steadystate conditions, besides mast cells, the peritoneal cavity mainly contains B1 lymphocytes and resident macrophages, neither of which secrete IL-4. Basophils, which are also potent producers of IL-4, were barely detectable in the peritoneal cavity before or after CLP, and the numbers of basophils in the circulation were identical in steady-state and septic conditions. Our data shown in Figure 3A clearly demonstrated that the observed difference in survival rates was dependent only mast cell deficiency, since basophils were totally replenished. Likewise, we observed no survival difference in RMB mice 6 days or 12 days after DT treatment, respectively, in the absence or presence of basophils (data not shown). Thus, basophils have no detectable effect on septic RMB mice. In mast cells, IL-4 is stored in secretory compartments, ready for secretion upon stimulation $(28,29,47)$. IL-4 is a pleiotropic cytokine with major immune regulatory functions, such as in naive $\mathrm{T}$ cell differentiation and Th2 polarization (48), alternative macrophage (M2 macrophage) differentiation, and proliferation of tissue-resident macrophages (49), ultimately playing an important role in tissue homeostasis and repair (32, 50). Of note, mast cells are essential for the differentiation of macrophages in milky spots of the peritoneal omentum, known to play an important role in pathogen elimination (51). Low amounts of bacteria or endotoxins may diffuse from the gut under steadystate conditions to weakly stimulate PMCs, thereby allowing the proliferation of resident macrophages and maintaining resident cell homeostasis and peritoneal tissue integrity.

In contrast, in acute inflammation, IL-4 impairs both macrophage phagocytosis and autophagy by altering the signaling pathways involved $(31,50)$ and decreases the expression of the macrophage class A scavenger receptor MARCO, which plays a key role in the phagocytosis of nonopsonized bacteria (52). Our data show that during sepsis, E. coli triggers the secretion of IL-4 from mast cells within 15 minutes in a TLR4-dependent manner. This secretion was not accompanied by the release of granule content (data not shown), an indication that, in these cells, IL-4 is not stored in histamine-containing granules, thus revealing a degree of selectivity for bacteria-induced IL-4 secretion. Furthermore, IL-4 increases MHC class II expression induced by IFN- $\gamma$ in mast cells (53). This, in turn, is thought to increase the ability of mast cells to mobilize $\mathrm{T}$ cells locally through antigen presentation. Thus, IL-4 production by mast cells in sepsis may represent an attempt by these cells to optimize their orchestration of the local immune response upon infection. However, since IL-4 production also resulted in a lower phagocytic response of resident macrophages, it may represent a strategy evolved by bacteria to divert the immune response and thereby escape the immune system. 
Taken together, our results show that resident peritoneal cells play a crucial role in the survival of mice during severe sepsis. Unexpectedly, mast cells, through the release of IL-4, reduce the capacity of resident macrophages to promote bacterial clearance. Thus, whereas IL-4 has been known for its role in enhancing Th2 immunity and the initiation of tissue repair, its inappropriate release during the initial stages of an overwhelming acute inflammatory reaction proved to be detrimental. In agreement with these findings, treatment with an IL-4-neutralizing antibody would lead to the reduction of mouse mortality following peritoneal infection (54). Therefore, the use of a humanized anti-IL-4 monoclonal antibody (such as pascolizumab, an antibody that was previously tested in asthma; ref. 55) could also be evaluated in the early phase of sepsis. Hence, our results demonstrate the important role of the crosstalk between resident hematopoietic cells such as mast cells and macrophages in the outcome of sepsis and indicate that the nature of the very early inflammatory response may be pivotal in determining survival following acute infection.

\section{Methods}

\section{Mice}

Generation of the RMB mouse (official name: B6; B6.Ms4a2 ${ }^{\text {tm1Mal }}$ ) is described in the Supplemental Methods. For mast cell and basophil depletion, mice were injected i.p. twice (2 days apart) with $1 \mu \mathrm{g}$ DT; littermate mice injected with PBS were used as controls.

\section{Cell culture}

BMMCs were obtained by culturing BM cells from the femurs and tib-

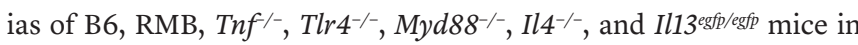
medium (RPMI-1640; 15\% FCS; $1 \%$ nonessential amino acids; $1 \mathrm{mM}$ $\mathrm{Na}$ pyruvate; $54 \mathrm{mM}$ 2-mercaptoethanol) containing recombinant murine IL-3 and stem cell factor (SCF) at $10 \mathrm{ng} / \mathrm{ml}$ (Peprotech) for 5 weeks. Cell suspensions contained more than $98 \%$ mast cells, as assessed by FACS analysis for $\mathrm{CD} 117^{+} \mathrm{Fc} \varepsilon \mathrm{RI}^{+}$expression. PDMCs were obtained from peritoneal lavage cells cultured in the presence of IL-3 and SCF, as for BMMCs.

\section{Flow cytometry}

Cells were stained with fluorochrome-conjugated monoclonal antibodies against mouse CD11b (M1/70); Ly6C (AL-21); Ly6G (1A8); 3 TCR (H57-597); CD45 (30-F11); CD19 (1D3); CD4 (RM4-5); SiglecF (E50-2440); and CD8 (53-6.7) (all from BD); I-A/I-E (M5/114.15.2); F4/80 (BM8); CD117 (ACK2); CD49b (DX5); and FceRI $\alpha$ (MAR-1) (all from eBioscience). After blocking Fc receptors with 2.4G2 supernatant, rat IgG and hamster IgG, cells were stained with the antibodies listed in the Supplemental Methods and diluted in PBS with 2\% FCS and $2 \mathrm{mM}$ EDTA for 30 minutes at $4^{\circ} \mathrm{C}$. In the blood, cells were gated as follows: after gating out doublets, the $\mathrm{CD} 45^{+}$cells were identified, then $\mathrm{CD} 19^{+}$ $B$ cells and $\beta \mathrm{TCR}^{+} \mathrm{T}$ cells $\left(\mathrm{CD}^{+}\right.$and $\left.\mathrm{CD} 8^{+}\right)$were gated. Among CD19 and $\beta \mathrm{TCR}^{-}$cells, neutrophils $\left(\mathrm{CD} 11 \mathrm{~b}^{+} \mathrm{Ly}_{6 \mathrm{G}^{+}}\right)$were detected. In the CD19- $\beta$ TCR $-\mathrm{Ly} 6 \mathrm{G}^{-}$cell population, the $\mathrm{ddT}^{+}$cells represented basophils, and in the $\operatorname{tdT}^{-}$population, eosinophils $\left(\mathrm{CD} 11 \mathrm{~b}^{+}\right.$SiglecF ${ }^{+} \mathrm{F} 4 / 80$ $\left.\mathrm{MHCII}^{-}\right)$and monocytes $\left(\mathrm{CD} 11 \mathrm{~b}^{+} \mathrm{Ly}_{6} \mathrm{G}^{-} \mathrm{Ly} 6 \mathrm{C}^{+}\right)$were identified. In the peritoneal cavity, lymphocytes and eosinophils were detected as above, mast cells were $\operatorname{tdT}^{+} \mathrm{Fc} \varepsilon \mathrm{RI} \alpha^{+} \mathrm{CD} 117^{+}$, and resident macrophages were $\mathrm{CD}_{11} \mathrm{~b}^{+} \mathrm{F} 4 / 80^{+} \mathrm{Ly} 6 \mathrm{G}^{-} \mathrm{Ly} 6 \mathrm{C}^{\mathrm{lo}}$, as previously described (56). Shortly after
CLP, massive recruitment of neutrophils and inflammatory monocytes $\left(\mathrm{CD} 11 \mathrm{~b}^{+} \mathrm{F} 4 / 80^{-} \mathrm{Ly}^{-} \mathrm{G}^{-} \mathrm{Ly} 6 \mathrm{C}^{+}\right)$were detected in the peritoneal cavity. Fluorescent cells were detected using a BD LSR Fortessa instrument with Diva software (BD Biosciences) and analyzed using FlowJo software (Tree Star Inc.). Cytokines released into the peritoneal cavity were analyzed after an i.p. injection of $1 \mathrm{ml}$ PBS by the CBA method (BD Biosciences), according to the manufacturer's instructions, on a FACSCanto II flow cytometer with Diva software. Hematological parameters were monitored in blood drawn from the retro-orbital plexus with an MS9-5 analyzer (Melet Schloesing).

\section{Phagocytosis}

For FACS analysis in vitro. Peritoneal macrophages $\left(0.1 \times 10^{6}\right)$ were cultured in 6-well plates in RPMI-1640 containing 1\% FCS. The next day, plates were washed, nonadherent cells were discarded, and adherent cells were kept for an additional 24 hours in RPMI with 10\% FCS. BMMCs $\left(4 \times 10^{6}\right)$ were starved of SCF overnight and activated for 2 hours with either $20 \times 10^{6}$ Texas Red fixed bacteria or $100 \mathrm{ng} / \mathrm{ml}$ LPS at $37^{\circ} \mathrm{C}$. Supernatants were filtered at $0.22 \mu \mathrm{m}$, mixed with $5 \times 10^{6}$ FITC-conjugated E. coli (Invitrogen), and added to macrophages for 15 minutes at $37^{\circ} \mathrm{C}$ to induce phagocytosis. Macrophages were washed twice with cold PBS and resuspended with PBS containing 5 mM EDTA before staining and acquisition on an LSR Fortessa instrument.

Confocal microscopic analysis in vitro. Peritoneal macrophages $\left(0.4 \times 10^{6}\right)$ were cultured in 8-well Permanox Lab-Tek slides in RPMI with $1 \%$ FCS overnight. The next day, nonadherent cells were discarded, and adherent cells were cultured in RPMI with 10\% FCS. SCFstarved BMMCs $\left(2 \times 10^{6}\right)$ were activated for 15 minutes with $10 \times 10^{6}$ E. coli at $37^{\circ} \mathrm{C}$. Supernatants were filtered at $0.22 \mu \mathrm{m}$, and $10 \mu \mathrm{g} / \mathrm{ml}$ anti-IL-4 (11B11; BioLegend) or anti-IL-13 antibody (eBio1316H) or control IgG (RTK2071; BioLegend) were added to the supernatant for 15 minutes at room temperature. Supernatants were mixed with $10 \times 10^{6}$ pHrodo-labeled bacteria (Invitrogen) and added to macrophages to assess phagocytosis. Macrophages were identified using a biotinylated anti-F4/80 antibody (BM8; eBioscience) and streptavidin-Alexa Fluor 488. Phagocytosis was assessed on a Zeiss LSM510 confocal microscope and analyzed using Imaris software. The median fluorescence intensity (MFI) of red fluorescence was calculated for each macrophage independently. To assess the inhibition of phagocytosis by IL-4, various concentrations of recombinant murine IL-4 (Peprotech) together with $10 \times 10^{6}$ pHrodo-labeled bacteria were added to macrophages for 15 minutes at $37^{\circ} \mathrm{C}$. Phagocytosis was stopped with 2 washes in ice-cold PBS.

FACS analysis in vivo. FITC-conjugated bacteria $\left(10 \times 10^{6}\right)$ were injected into the peritoneal cavity of RMB mice pretreated with PBS or DT 12 days before, or into B6 or Kit $t^{W-s h / W-s h}$ mice. Mice were sacrificed 15 minutes after injection. Peritoneal cells were stained as described above and analyzed by FACS.

\section{CLP}

Peritonitis was induced by CLP in male mice 12 days after PBS or DT injection, as previously described (23). Only male mice were used, and all surgeries were performed within 15 minutes per mouse, with a maximum of 8 mice per procedure starting at $10 \mathrm{am}$. No animal was excluded from the test. After anesthesia, the abdomen was shaved, and the cecum was exposed through a $1-\mathrm{cm}$ midline incision. The cecum was ligated at three-quarters of its length with a no. 5 silk suture (Ethicon) and punctured once with a 21-gauge needle. The cecum was replaced, 
and $1 \mathrm{ml}$ sterile saline $(0.9 \% \mathrm{NaCl})$ prewarmed to $37^{\circ} \mathrm{C}$ was injected into the peritoneal cavity. In some experiments, $10 \mu \mathrm{g}$ per mouse of an anti-IL-4 antibody or a control IgG antibody was injected concurrently with skin closure. For mast cell reconstitution, BMMCs $\left(2.5 \times 10^{6}\right)$ were injected i.p. into 4-week-old RMB mice following DT treatment. The mice were used for CLP 8 weeks later (DT was reinjected 12 days before the CLP procedure). Mouse survival was monitored every 8 hours for the first 3 days and then every 12 hours until day 7.

\section{Passive systemic anaphylaxis and IL-4 secretion assay}

See Supplemental Methods for details.

\section{General experimental design and statistical analysis}

For animal experiments, littermates were used and randomly distributed in PBS or DT treatment groups. Statistical analysis significance was calculated using GraphPad Prism software. Kaplan-Meier survival curves and the log-rank test were applied for mice survival, and the differences in $P$ values between 2 groups were determined using with the nonparametric Mann-Whitney $U$ test. Data are presented as the means \pm SEM, and $P$ values of less than 0.05 were considered significant.

\section{Study approval}

$\mathrm{RMB}, \mathrm{C} 57 \mathrm{Bl} / 6$, and $\mathrm{Kit}^{\mathrm{W}-\mathrm{sh} / \mathrm{W}-\mathrm{sh}}$ mice were housed under specific pathogen-free conditions at the mouse facilities of Bichat Medical School. Mice used in all experiments were 10-14 weeks of age. All animal exper- imental protocols were approved by the French Agricultural Office and the INSERM ethics committee, and all animal care and experimentation were conducted in accordance with European directives.

\section{Acknowledgments}

We thank Andrew McKenzie (MRC, Cambridge, United Kingdom) for providing IL-13 eGFP bone marrow; Maria Leite-de-Moraes (CNRS UMR 8147) for Il4 ${ }^{--}$BM cells; Bernard Ryffel (CNRS UMR6218) for Il4ra/- BM cells; and Ana-Maria Lennon (INSERM U932) for $\mathrm{Tlr}^{-/-}$and $M y d 88^{-/-}$BM cells. We thank Loredana Saveanu (INSERM U1013) for the acidification phagosome assay. We thank Julie Bex and Nathalie Ialy-Radio for help with animal care. We thank Sandrine Henry (CNRS UMS3367) for scientific advice. The RMB mouse model was developed within the framework of the Centre d'Immunophénomique and supported by the Fondation pour la Recherche Médicale (FRM) (DAL2007082005, to P. Launay, B. Malissen, M. Daëron, and U. Blank). G. Gautier was supported by the FRM; A. Dahdah and T. Attout were supported by the ANR Genopath (09-GENO-026); and P. Launay was supported by the INSERM (Avenir grant).

Address correspondence to: Pierre Launay, INSERM U1149, Faculté de Médecine Paris Diderot - Site Xavier Bichat -16, Rue Henri Huchard, 75018 Paris Cedex 18, France. Phone: 33.1.5727.7756; E-mail: pierre.launay@inserm.fr.
1. Soehnlein O, Lindbom L. Phagocyte partnership during the onset and resolution of inflammation. Nat Rev Immunol. 2010;10(6):427-439.

2. Hotchkiss RS, Karl IE. The pathophysiology and treatment of sepsis. N Engl J Med. 2003;348(2):138-150.

3. Tsai M, Grimbaldeston M, Galli SJ. Mast cells and immunoregulation/immunomodulation. $A d v$ Exp Med Biol. 2011;716:186-211.

4. Beghdadi W, et al. Mast cells as cellular sensors in inflammation and immunity. Front Immunol. 2011;2:37.

5. Chan CY, St John AL, Abraham SN. Mast cell interleukin-10 drives localized tolerance in chronic bladder infection. Immunity. 2013;38(2):349-359.

6. Gilfillan AM, Beaven MA. Regulation of mast cell responses in health and disease. Crit Rev Immunol. 2011;31(6):475-529.

7. de Vries VC, Noelle RJ. Mast cell mediators in tolerance. Curr Opin Immunol. 2010;22(5):643-648.

8. Serafini N, et al. The TRPM4 channel controls monocyte and macrophage, but not neutrophil, function for survival in sepsis. J Immunol. 2012;189(7):3689-3699.

9. Huang X, et al. PD-1 expression by macrophages plays a pathologic role in altering microbial clearance and the innate inflammatory response to sepsis. Proc Natl Acad Sci U S A. 2009;106(15):6303-6308.

10. Echtenacher B, Mannel DN, Hultner L. Critical protective role of mast cells in a model of acute septic peritonitis. Nature. 1996;381(6577):75-77.

11. Prodeus AP, Zhou X, Maurer M, Galli SJ, Carroll MC. Impaired mast cell-dependent natural immunity in complement C3-deficient mice.
Nature. 1997;390(6656):172-175.

12. Maurer M, et al. Mast cells promote homeostasis by limiting endothelin-1-induced toxicity. Nature. 2004;432(7016):512-516.

13. Mallen-St Clair J, Pham CT, Villalta SA, Caughey GH, Wolters PJ. Mast cell dipeptidyl peptidase I mediates survival from sepsis. JClin Invest. 2004;113(4):628-634

14. Orinska Z, et al. IL-15 constrains mast cell-dependent antibacterial defenses by suppressing chy mase activities. Nat Med. 2007;13(8):927-934.

15. Sutherland RE, Olsen JS, McKinstry A, Villalta SA, Wolters PJ. Mast cell IL-6 improves survival from Klebsiella pneumonia and sepsis by enhancing neutrophil killing. J Immunol. 2008;181(8):5598-5605.

16. Piliponsky AM, et al. Neurotensin increases mortality and mast cells reduce neurotensin levels in a mouse model of sepsis. Nat Med. 2008;14(4):392-398.

17. Piliponsky AM, et al. Mast cell-derived TNF can exacerbate mortality during severe bacterial infections in C57BL/6-KitW-sh/W-sh mice. $A m J$ Pathol. 2010;176(2):926-938.

18. Brown MA, Hatfield JK, Walker ME, Sayed BA. A game of kit and mouse: the Kit is still in the bag. Immunity. 2012;36(6):891-892.

19. Kinet JP, Blank U, Ra C, White K, Metzger H, Kochan J. Isolation and characterization of cDNAs coding for the beta subunit of the high-affinity receptor for immunoglobulin E. Proc Natl Acad Sci U S A. 1988;85(17):6483-6487.

20. Blank U, Ra C, Miller L, White K, Metzger H, Kinet JP. Complete structure and expression in transfected cells of high affinity IgE receptor. Nature. 1989;337(6203):187-189.
21. Drew E, Merzaban JS, Seo W, Ziltener HJ, McNagny KM. CD34 and CD43 inhibit mast cell adhesion and are required for optimal mast cell reconstitution. Immunity. 2005;22(1):43-57.

22. Rodewald HR, Feyerabend TB. Widespread immunological functions of mast cells: fact or fiction? Immunity. 2012;37(1):13-24.

23. Pinheiro da Silva F, et al. CD16 promotes Escherichia coli sepsis through an FcR gamma inhibitory pathway that prevents phagocytosis and facilitates inflammation. Nat Med. 2007;13(11):1368-1374.

24. Rittirsch D, Huber-Lang MS, Flierl MA, Ward PA. Immunodesign of experimental sepsis by cecal ligation and puncture. Nat Protoc. 2009;4(1):31-36.

25. Cohen J. The immunopathogenesis of sepsis. Nature. 2002;420(6917):885-891.

26. Barth MW, Hendrzak JA, Melnicoff MJ, Morahan PS. Review of the macrophage disappearance reaction. JLeukoc Biol. 1995;57(3):361-367.

27. Goldszmid RS, et al. NK cell-derived interferon- $\gamma$ orchestrates cellular dynamics and the differentiation of monocytes into dendritic cells at the site of infection. Immunity. 2012;36(6):1047-1059.

28. Brown MA, Pierce JH, Watson CJ, Falco J, Ihle JN, Paul WE. B cell stimulatory factor-1/interleukin-4 mRNA is expressed by normal and transformed mast cells. Cell. 1987;50(5):809-818.

29. Bradding $P$, et al. Interleukin 4 is localized to and released by human mast cells. J Exp Med. 1992;176(5):1381-1386.

30. Gessner A, Mohrs K, Mohrs M. Mast cells, basophils, and eosinophils acquire constitutive IL-4 and IL-13 transcripts during lineage differentiation that are sufficient for rapid cytokine production. JImmunol. 2005;174(2):1063-1072. 
31. Varin A, Mukhopadhyay S, Herbein G, Gordon S. Alternative activation of macrophages by IL-4 impairs phagocytosis of pathogens but potentiates microbial-induced signalling and cytokine secretion. Blood. 2010;115(2):353-362.

32. Van Dyken SJ, Locksley RM. Interleukin-4- and interleukin-13-mediated alternatively activated macrophages: roles in homeostasis and disease. Annu Rev Immunol. 2013;31:317-343.

33. Galli SJ, Grimbaldeston M, Tsai M. Immunomodulatory mast cells: negative, as well as positive, regulators of immunity. Nat Rev Immunol. 2008;8(6):478-486.

34. Abraham SN, St John AL. Mast cell-orchestrated immunity to pathogens. Nat Rev Immunol. 2010;10(6):440-452.

35. Nakamura Y, et al. Staphylococcus delta-toxin induces allergic skin disease by activating mast cells. Nature. 2013;503(7476):397-401.

36. Choi HW, et al. Salmonella typhimurium impedes innate immunity with a mast-cellsuppressing protein tyrosine phosphatase, SptP. Immunity. 2013;39(6):1108-1120.

37. Du T, Friend DS, Austen KF, Katz HR. Tissue-dependent differences in the asynchronous appearance of mast cells in normal mice and in congenic mast cell-deficient mice after infusion of normal bone marrow cells. Clin Exp Immunol. 1996;103(2):316-321.

38. Grimbaldeston MA, Chen CC, Piliponsky AM, Tsai M, Tam SY, Galli SJ. Mast cell-deficient $\mathrm{W}$-sash c-kit mutant Kit W-sh/W-sh mice as a model for investigating mast cell biology in vivo. Am J Pathol. 2005;167(3):835-848.

39. Dudeck A, et al. Mast cells are key promoters of contact allergy that mediate the adjuvant effects of haptens. Immunity. 2011;34(6):973-984.

40. Feyerabend TB, et al. Cre-mediated cell ablation contests mast cell contribution in models of antibody- and T cell-mediated autoimmunity. Immunity. 2011;35(5):832-844.

41. Lilla JN, et al. Reduced mast cell and basophil numbers and function in Cpa3-Cre; $\mathrm{Mcl}-1 \mathrm{fl} / \mathrm{fl}$ mice. Blood. 2011;118(26):6930-6938.

42. Malaviya R, Abraham SN. Mast cell modulation of immune responses to bacteria. Immunol Rev. 2001;179:16-24.

43. Gordon JR, Galli SJ. Mast cells as a source of both preformed and immunologically inducible TNF- $\alpha$ / cachectin. Nature. 1990;346(6281):274-276.

44. Bozza M, et al. Targeted disruption of migration inhibitory factor gene reveals its critical role in sepsis. J Exp Med.1999;189(2):341-346.

45. Wollenberg GK, DeForge LE, Bolgos G, Remick DG. Differential expression of tumor necrosis factor and interleukin- 6 by peritoneal macrophages in vivo and in culture. Am J Pathol. 1993;143(4):1121-1130.

46. Cui W, Morrison DC, Silverstein R. Differential tumor necrosis factor alpha expression and release from peritoneal mouse macrophages in vitro in response to proliferating gram-positive versus gram-negative bacteria. Infect Immun . 2000;68(8):4422-4429.

47. Jobbings CE, Sandig H, Whittingham-Dowd JK, Roberts IS, Bulfone-Paus S. Listeria monocytogenes alters mast cell phenotype, mediator and osteopontin secretion in a listeriolysin-dependent manner. PLoS One. 2013;8(2):e57102.

48. Nelms K, Keegan AD, Zamorano J, Ryan JJ, Paul WE. The IL-4 receptor: signaling mechanisms and biologic functions. Annu Rev Immunol.
1999;17:701-738.

49. Jenkins SJ, et al. Local macrophage proliferation, rather than recruitment from the blood, is a signature of TH2 inflammation. Science. 2011;332(6035):1284-1288.

50. Stein M, Keshav S, Harris N, Gordon S. Interleukin 4 potently enhances murine macrophage mannose receptor activity: a marker of alternative immunologic macrophage activation. J Exp Med.1992;176(1):287-292.

51. Zareie M, et al. Novel role for mast cells in omental tissue remodeling and cell recruitment in experimental peritoneal dialysis. J Am Soc Nephrol. 2006;17(12):3447-3457.

52. Jozefowski S, Arredouani M, Sulahian T, Kobzik L. Disparate regulation and function of the class A scavenger receptors SR-AI/II and MARCO. J Immunol. 2005;175(12):8032-8041.

53. Gaudenzio N, Espagnolle N, Mars LT, Liblau R, Valitutti S, Espinosa E. Cell-cell cooperation at the T helper cell/mast cell immunological synapse. Blood. 2009;114(24):4979-4988.

54. Song GY, Chung CS, Chaudry IH, Ayala A. IL-4-induced activation of the Stat6 pathway contributes to the suppression of cell-mediated immunity and death in sepsis. Surgery. 2000;128(2):133-138.

55. Hart TK, et al. Preclinical efficacy and safety of pascolizumab (SB 240683): a humanized anti-interleukin-4 antibody with therapeutic potential in asthma. Clin Exp Immunol. 2002;130(1):93-100.

56. Ghosn EE, et al. Two physically, functionally, and developmentally distinct peritoneal macrophage subsets. Proc Natl Acad Sci US A. 2010;107(6):2568-2573. 